\title{
A systematic literature review of the clinical and health economic burden of schizophrenia in privately insured patients in the United States
}

This article was published in the following Dove Press journal:

ClinicoEconomics and Outcomes Research

\author{
Wenjie Zhang' \\ Tony B Amos ${ }^{2}$ \\ Stephen W Gutkin' \\ Nicole Lodowski' \\ Emma Giegerich' \\ Kruti Joshi ${ }^{2}$
}

'WG US Advanced Health Analytics (WG AHA), Stamford, CT, USA; 2Janssen Scientific Affairs, LLC, Titusville, NJ, USA
Correspondence: Wenjie Zhang WG AHA, 1010 Washington Blvd, Stamford CT 06091, USA

$\mathrm{Tel}+\mathrm{I} 3478026388$

Email wenjie.zhang@wg-group.com
Purpose: The aim of this study was to conduct a systematic literature review on the burden of schizophrenia in privately insured US patients.

Materials and methods: A systematic literature review of English language peer-reviewed journal articles of observational studies published from 2006 to 2016 was conducted using EMBASE/MEDLINE databases. Abstracts covering substantial numbers of patients with schizophrenia or schizoaffective disorder (i.e., $\mathrm{N} \geq 100$ ) were included for full-text review. Articles that did not clearly specify private insurance types were excluded.

Results: A total of 25 studies were reviewed; 10 included only privately insured patients; and 15 included a mix of different types of insurance. The review of the clinical burden of schizophrenia revealed the following: compared to patients with no mental disorders, those with schizophrenia had significantly increased odds of systemic disorders and both alcohol and substance abuse. Antipsychotic (AP) adherence was low, ranging from 31.5\% to $68.7 \%$. The medication possession ratio for AP adherence ranged from 0.22 to 0.73 . The review of the health economic burden of schizophrenia revealed the following: patients with a recent (vs. chronic) diagnosis of schizophrenia had significantly higher frequencies of emergency department visits and hospitalizations and greater length of stay (LOS) and total annual per-capita costs. Mean all-cause hospitalizations and LOS decreased significantly after (vs. before) initiating long-acting injectable APs (LAIs). Patients also had significantly decreased mean all-cause, and schizophrenia-related, hospitalization costs after initiating LAIs. Total direct per-capita costs of care (but not pharmacy costs) for patients who were nonadherent to their oral APs within the first 90 days of their index event were significantly higher (vs. early adherent patients). Despite these potential benefits, only $0.25 \%-13.1 \%$ of patients were treated with LAIs across all studies.

Conclusion: Privately insured US patients with schizophrenia experience a substantial clinical and health economic burden related to comorbidities, acute care needs, nonadherence, and polypharmacy and have relatively low use of LAIs. Further study is warranted to understand prescribing patterns and clinical policies related to this patient population.

Keywords: adherence, burden of illness, comorbidity, cost, health resource utilization, schizophrenia

\section{Introduction}

Schizophrenia is a serious public health problem affecting approximately $1.1 \%$ of the world's population, which includes about 3.5 million patients diagnosed in the United States; the annual incidence rate ranges from 10.2 to 22.0 per 100,000 person-years. ${ }^{1,2}$ It is one of the top 10 causes of disability around the world, and the mean life expectancy in Americans with schizophrenia is $12-15$ years lower than in the general population. ${ }^{3}$ 
Many patients with schizophrenia also suffer from substantial comorbidities and poor overall health habits, including personal neglect as well as alcohol and substance abuse. ${ }^{3}$ Furthermore, nearly $40 \%$ of patients with schizophrenia in North America attempt suicide at some time in their lives, culminating in death by suicide in $10 \% .^{4,5}$

This profound psychiatric disorder often has its onset during an individual's (otherwise) most formative and productive years, with nearly $75 \%$ of patients developing schizophrenia between the ages of 16 and 25 years. ${ }^{1}$ The condition is also often associated with socioeconomic deprivation, and most adults with schizophrenia receive government health insurance; only $15 \%$ are covered by private insurance plans. ${ }^{6,7}$

Under the Patient Protection and Affordable Care Act (ACA) of 2010, which mandates coverage up to 26 years of age, many patients with early-onset schizophrenia are now insured under their parents' employer-based health plans. According to projections from the Centers for Medicare \& Medicaid Services (CMS), the impact of the federal mandate extension of commercial coverage would result in 1.2 million young adults receiving care under their parents' health plans. ${ }^{8}$ Although the prevalence of schizophrenia in privately insured patient populations is low, the overall annual US cost burden of schizophrenia is up to $\$ 63$ billion, including about $\$ 23$ billion $(\sim 35 \%)$ in excess direct health care costs $(\$ 8.0$ billion for long-term care; $\$ 7.0$ billion for outpatient care; $\$ 5$ billion for medications; and $\$ 2.8$ billion for hospitalization); $\$ 9$ billion $(\sim 15 \%)$ in direct non-health care costs; and $\$ 32.4$ billion $(\sim 50 \%)$ in total excess indirect costs. ${ }^{9}$

Given a potential imminent rise in numbers of patients suffering from schizophrenia who are covered by private insurance plans, and the seriousness of this public health problem, many health care providers and other decision makers would benefit by developing an enhanced understanding of the burden of illness and unmet need of this population. Most of the contemporary understanding of the clinical and health economic (HE) burden of schizophrenia in the US has been built from studies of patients covered under publicly funded health insurance plans. Much less is known about the burden of schizophrenia in privately insured patients. Thus, the chief objective of this study was to review available real-world evidence (RWE) studies focusing on the clinical and HE burden of schizophrenia in privately insured populations.

\section{Materials and methods}

An EMBASE/MEDLINE search of peer-reviewed journal articles of observational studies in the English language clinical and HE literature, published from 2006 to 2016, was conducted. The search terms were grouped into "patient type" (e.g., "schiz*" AND "commercially insured" OR "privately insured" OR “employer sponsored"), "treatment options" (e.g., "antipsychotic” OR “antipsychotics” OR “depot” OR "LAI” OR "long-acting” OR “injectable” OR “oral medication), "clinical burden" (e.g., "relapse” OR "hospitalization" OR “admission*” OR "emergen*" OR “emergency room" OR “emergency department” OR “comorbidity” OR “remission" OR “outpatient” OR “inpatient” OR “discontinuation" OR "adherence"), and "health economic burden" (e.g., "financ*" OR "economic*" OR "cost*" OR "resource*" OR "utiliz*"). Search terms are tabulated in Table S1.

To enrich the output, a supplementary search in PubMed was conducted. This search crossed key terms (using the Boolean operator "AND") with the names of leading HE journals (i.e., Journal of Managed Care Pharmacy, Journal of Medical Economics, Pharmacoeconomics, and Value in Health).

Abstracts of studies that evaluated the burden of schizophrenia in patients with private (i.e., mainly employer-based) insurance plans were reviewed. Reports of studies that included $\geq 100$ patients with schizophrenia or schizoaffective disorder were included for full-text review. Any studies that assessed iatrogenic medication effects or did not specify private insurance were excluded.

The Preferred Reporting Items for Systematic Reviews and Meta-Analyses (PRISMA) flowchart, which details the search and supplementary search strategies and outcomes, is shown in Figure 1.

\section{Results}

\section{Patient characteristics}

After screening 1,578 unique citations, we retained 25 fulllength peer-reviewed articles for the current study. 2,6,7,10-31 In total, this study encompassed 81,327 privately insured patients with schizophrenia and other related disorders, as categorized (in most studies reviewed in this study) by the International Classification of Diseases, Ninth Revision, Clinical Modification (ICD-9-CM) code of 295.xx.

Of the 25 studies covered in this literature review, 10 included only privately insured patients, and 15 included patients with a mix of different types of insurance. Privately insured patients with schizophrenia accounted for nearly half of the sample population within the systematic literature review. A total of $45.5 \%$ of patients had private insurance, $54.1 \%$ were covered under public plans (Medicare, Medicaid, Veterans Affairs), and the insurance status of the remaining 


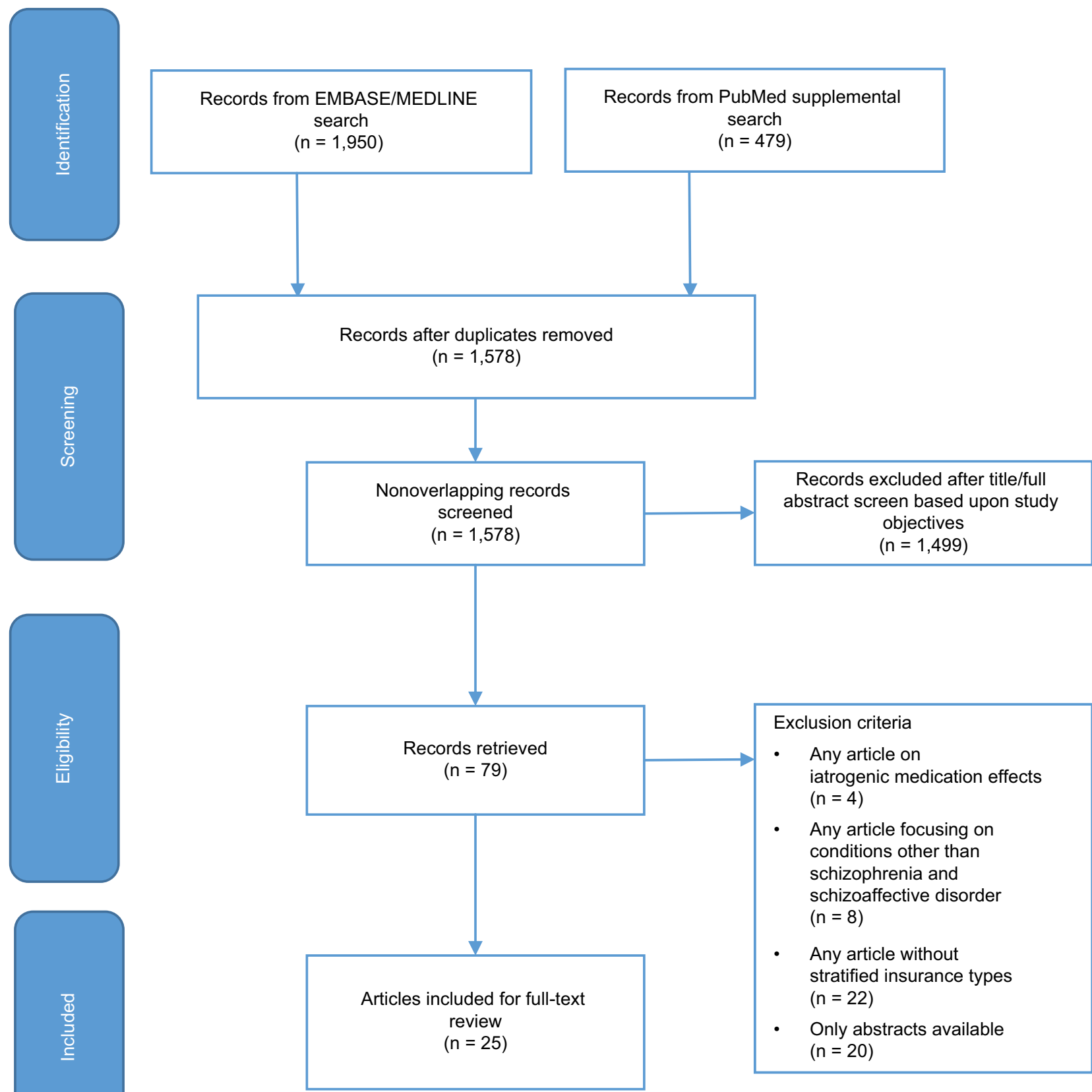

Figure I PRISMA flowchart depicting search strategy and outcomes of the systematic literature review. Abbreviation: PRISMA, Preferred Reporting Items for Systematic Reviews and Meta-Analyses.

$0.4 \%$ was unknown. Only data on privately insured patients are presented in the "Results" section of this study.

Patient demographics are summarized in Table 1.

\section{Key findings on clinical burden of schizophrenia}

\section{Clinical burden of nonremitting disease}

One study report was appropriate for, and reviewed in, this section. $^{12}$
The 3-year prospective US Schizophrenia Case and Assessment Program (US-SCAP) study, which investigated the clinical and functional elements of remission in 2,284 adults with schizophrenia (or schizoaffective/ schizophreniform disorder), found that patients who were not in remission at enrollment had significantly lower adherence to medication regimens $(p<0.001)$ and greater impairment of functional status and health-related quality of life. $^{12}$ 
Table I Patient characteristics

\begin{tabular}{|c|c|c|c|c|}
\hline Study & $\begin{array}{l}\text { No. of patients } \\
\text { commercially insured (\%) }\end{array}$ & Age (mean) (years) & $\operatorname{Sex}(\%)$ & US region ${ }^{b}$ \\
\hline Carney et $\mathrm{al}^{13}$ & $1,074(100)$ & 40.2 & M: 47.0; F: 53.0 & lowa residents only \\
\hline Cloutier et al" & $31,698(29.6)$ & $\mathrm{N} / \mathrm{A}$ & N/A & Nationally representative \\
\hline Dodds et $\mathrm{al}^{25}$ & $18(37.5)$ & 22.2 & M: 89.6; F: 10.4 & Connecticut residents only \\
\hline Fisher et $\mathrm{a}^{20}$ & $4,156(100)$ & 40 & M: 53.I; F: 46.9 & Nationally representative \\
\hline Fitch et $\mathrm{a}^{26}$ & $8,985(100)$ & $N / A$ & $N / A$ & Nationally representative \\
\hline $\begin{array}{l}\text { Gianfrancesco } \\
\text { et al }{ }^{\mid 1}\end{array}$ & $3,807(100)$ & 41.2 & M: 38.8; F: 61.2 & Nationally representative \\
\hline Gibson et $\mathrm{al}^{15}$ & $\mathrm{I}, 392(17.6)$ & 42.8 & M: 38.0; F: 62.0 & $\begin{array}{l}\text { Northeast: } 8.6 \% \\
\text { North Central: } 33.0 \% \\
\text { South: } 36.4 \% \\
\text { West: } 21.6 \% \\
\text { Unknown region: } 0.4 \%\end{array}$ \\
\hline Haynes et $\mathrm{al}^{12}$ & $94(4.1)$ & 41.8 & M: 6I.6; F: 38.4 & $\begin{array}{l}\text { California, Colorado, Connecticut, Florida, } \\
\text { Maryland, and North Carolina }\end{array}$ \\
\hline Joshi et al ${ }^{16}$ & $2,713(100)$ & 40.2 & M: 47.3; F: 52.7 & $\begin{array}{l}\text { Midwest: } 29.0 \% \\
\text { Northeast: } 13.5 \% \\
\text { South: } 44.1 \% \\
\text { West: } 13.4 \%\end{array}$ \\
\hline Khaykin et $\mathrm{al}^{6}$ & $42(12.3)$ & N/A & M: 58.3; F: 41.7 & $\begin{array}{l}\text { Northeast: } 8.6 \% \\
\text { Midwest: } 26.4 \% \\
\text { South: } 35.0 \% \\
\text { West: } 30.0 \%\end{array}$ \\
\hline Kim et al ${ }^{17}$ & $84(23.9)$ & 43.4 & M: 44.4; F: 55.6 & N/A \\
\hline Lafeuille et $\mathrm{al}^{27}$ & $386(3.5)$ & $\begin{array}{l}\text { LAI: } 42.1 \\
\text { Oral: } 42.4\end{array}$ & $\begin{array}{l}\text { LAl vs. oral } \\
\text { M: } 56.4 \text { vs. } 55.4 \\
\text { F: } 43.6 \text { vs. } 44.6\end{array}$ & $\begin{array}{l}\text { South: } 41.2 \% \\
\text { Midwest: } 25.1 \% \\
\text { West: } 17.6 \% \\
\text { Northeast: } 16.1 \%\end{array}$ \\
\hline Lang et $\mathrm{al}^{7}$ & $7,528(26.7)$ & 47.9 & M: 47.0; F: 53 & N/A \\
\hline Lin et $\mathrm{a}^{10}$ & $3,004(81.9)$ & LAI: 4 I.7 & LAl vs. oral & LAl vs. oral \\
\hline Offord et al ${ }^{18}$ & & Oral: 37.1 & $\begin{array}{l}\text { M: } 5 \text { I. } 8 \text { vs. } 50.3 \\
\text { F: } 48.2 \text { vs. } 49.7\end{array}$ & $\begin{array}{l}\text { Northeast: II. } 2 \% \text { vs. II. } 3 \% \\
\text { North Central: } 47.0 \% \text { vs. } 29.5 \% \\
\text { South: } 32.0 \% \text { vs. } 33.5 \% \\
\text { West: } 9.4 \% \text { vs. } 24.9 \%\end{array}$ \\
\hline McCombs et $\mathrm{al}^{23}$ & $5,909(100)$ & 41.3 & M: 37.6; F: 62.4 & $N / A$ \\
\hline Nicholl et al ${ }^{14}$ & $3,187(80.4)$ & $\begin{array}{l}\text { Recently diagnosed } \\
\text { patients: } 28.1 \\
\text { Chronic patients: } 45.4\end{array}$ & $\begin{array}{l}\text { Recently diagnosed } \\
\text { vs. chronic } \\
\text { M: } 56.7 \text { vs. } 48.2 \\
\text { F: } 43.3 \text { vs. } 51.8\end{array}$ & $\begin{array}{l}\text { Recently diagnosed vs. chronic } \\
\text { Northeast: } 20.8 \% \text { vs. } 24.4 \% \\
\text { Midwest: } 56.9 \% \text { vs. } 54.6 \% \\
\text { South: } 10.9 \% \text { vs. } 10.5 \% \\
\text { West: } 11.3 \% \text { vs. } 10.6 \%\end{array}$ \\
\hline Offord et $\mathrm{a}^{2}$ & $1,462(100)$ & $\begin{array}{l}\text { Nonadherent: } 38.6 \\
\text { Adherent: } 39.9\end{array}$ & $\mathrm{~N} / \mathrm{A}$ & $\begin{array}{l}\text { Nonadherent vs. adherent } \\
\text { Northeast: } 1 \text { I. } 2 \% \text { vs. } 10.2 \% \\
\text { North Central: } 31.6 \% \text { vs. } 34.3 \% \\
\text { South: } 36.9 \% \text { vs. } 31.1 \% \\
\text { West: } 19.6 \% \text { vs. } 23.6 \% \\
\text { Unknown: } 0.7 \% \text { vs. } 0.9 \%\end{array}$ \\
\hline Panish et $\mathrm{a}^{28}$ & $562(100)$ & 43.5 & M: 37.7; F: 62.3 & $\begin{array}{l}\text { New England: } 2.5 \% \\
\text { Mid-Atlantic: } 4.8 \% \\
\text { East North Central: } 7.8 \% \\
\text { West North Central: } 15.1 \% \\
\text { South Atlantic: } 36.5 \% \\
\text { East South Central: } 3.9 \% \\
\text { West South Central: } 16.0 \% \\
\text { Mountain: } 9.8 \% \\
\text { Pacific: } 3.6 \%\end{array}$ \\
\hline Pyenson et al ${ }^{19}$ & $4,665(50.3)$ & 39.4 & M: 50; F: 50 & $N / A$ \\
\hline Peng et $\mathrm{a}^{24}$ & $147(100)$ & 42.6 & M: 53.7; F: 46.3 & $\mathrm{~N} / \mathrm{A}$ \\
\hline
\end{tabular}


Table I (Continued)

\begin{tabular}{|c|c|c|c|c|}
\hline Study & $\begin{array}{l}\text { No. of patients } \\
\text { commercially insured (\%) }\end{array}$ & Age (mean) (years) & $\operatorname{Sex}(\%)$ & US region ${ }^{b}$ \\
\hline Rost et $\mathrm{al}^{22}$ & $\begin{array}{l}\text { N/A } \\
3,359 \text { outpatient visits }\end{array}$ & $N / A$ & M: 54.I; F: 45.9 & $\begin{array}{l}\text { Northeast: } 33.0 \% \\
\text { Midwest: } 16.9 \% \\
\text { South: } 29.6 \% \\
\text { West: } 20.5 \%\end{array}$ \\
\hline Stensland et $\mathrm{al}^{29}$ & $\begin{array}{l}\text { N/A } \\
\text { Only numbers of psychiatric } \\
\text { hospitalizations available }\end{array}$ & $\mathrm{N} / \mathrm{A}$ & $\mathrm{N} / \mathrm{A}$ & $\mathrm{N} / \mathrm{A}$ \\
\hline Wang and Farley ${ }^{30 c}$ & I.89 million & $\mathrm{N} / \mathrm{A}$ & M: 49 vs. F: 51 & $\begin{array}{l}\text { Atypical AP vs. typical AP } \\
\text { Northeast: } 24.08 \% \text { vs. } 30.33 \% \\
\text { Midwest: } 23.51 \% \text { vs. } 23.66 \% \\
\text { South: } 34.34 \% \text { vs. } 25.76 \% \\
\text { West: } 18.08 \% \text { vs. } 20.26 \%\end{array}$ \\
\hline Wilson et $\mathrm{al}^{21}$ & $4 \mid 4$ & 36.5 & M: 49.4; F: 50.6 & California \\
\hline
\end{tabular}

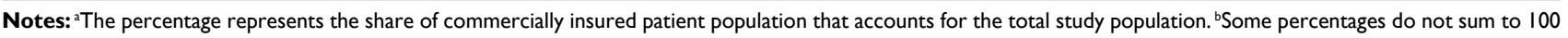
because of rounding. 'Patients were not included in health resource utilization calculations.

Abbreviations: AP, antipsychotic; F, female; LAI, long-acting injectable AP; M, male; N/A, not available.

\section{Clinical burden of comorbidities}

One study report was appropriate for, and reviewed in, this section. ${ }^{13}$

A retrospective analysis of longitudinal administrative claims data from patients with schizophrenia (or schizoaffective disorder; i.e., cases) and 726,262 patients who filed at least one claim for medical services (but not for mental disorders, i.e., controls) from 1996 to 2001 in the Iowa Wellmark Blue Cross/Blue Shield plan, evaluated comorbidities. This study revealed that $33 \%$ of the studied population with schizophrenia $(n=1,074)$ had $\geq 3$ chronic medical comorbidities, and only $29 \%$ of patients with schizophrenia had no claims for comorbid conditions. ${ }^{13}$

Compared to patients with no mental disorders, individuals with schizophrenia had significantly increased odds of conditions that can adversely affect clinical outcomes, including 1) an approximately twofold increased odds of certain systemic disorders (e.g., odds ratio $[\mathrm{OR}]=2.62 ; 95 \%$ confidence interval $[\mathrm{CI}]=2.09-3.28$ for hypothyroidism and 2.11 [95\% CI $=1.36-3.28]$ for diabetes with complications); 2) an approximately 10-fold increased odds of other neurologic conditions $(\mathrm{OR}=9.67 ; 95 \% \mathrm{CI}=7.66-12.21) ; 3$ ) an approximately 12-fold increased odds of alcohol abuse/ dependence $(\mathrm{OR}=12.57 ; 95 \% \mathrm{CI}=10.16-15.55)$; and 4$)$ a 35 -fold increased odds of illicit substance abuse/dependence $(\mathrm{OR}=35.42 ; 95 \% \mathrm{CI}=28.35-44.27) .^{13}$

\section{Clinical burden of nonadherence and effects of long- acting injectable antipsychotic (LAl) regimens}

Table 2 summarizes most reviewed studies that evaluated nonadherence among patients with schizophrenia. ${ }^{2,7,12,16-19}$
Overall, medication adherence was suboptimal, ranging from $31.5 \%$ to $68.7 \% .^{15,17}$

According to studies included in this review, the medication possession ratio (MPR) for antipsychotic (AP) adherence ranged from 0.22 to 0.73 in privately insured patients (Table 2). ${ }^{2,18}$ In a study of the Thomson Reuters MarketScan IMS LifeLink database of AP prescriptions from January 1, 2008 , to June $30,2009,44.6 \%$ of privately insured patients were nonadherent at a threshold for nonadherence of MPR $<0.80$ during the 1-year follow-up period. ${ }^{7}$ Patients who either newly initiated APs or were nonadherent at baseline had an eightfold increase in AP nonadherence over 1 year of follow-up. ${ }^{7}$

Another study that included patients with schizophrenia focused on treatment adherence among individuals with schizoaffective disorder and either incident or prevalent disease who had records in the Clinformatics Data Mart database from January 1, 2009, to December 31, 2012. For the purposes of analysis, patients designated to have incident schizoaffective disorder had no claims for this condition during the 12 months before the index date, while those with prevalent disease did have claims in this baseline period. ${ }^{16}$ Of all privately insured patients, $51 \%$ were nonadherent according to an MPR $<0.80$ and $62 \%$ according to a proportion of days covered $(\mathrm{PDC})<0.80$. Patients with incident (vs. prevalent) disease had significantly greater nonadherence $(55.1 \%$ vs. $41.3 \%$, respectively $[p<0.001]$ by MPR $<0.80$ and $66.4 \%$ vs. $51.5 \%$, respectively $[p<0.001]$ by $\mathrm{PDC}<0.80) .{ }^{16}$

Across studies, proportions of patients using LAIs ranged from $0.25 \%{ }^{31}$ to $13.1 \% .^{10,16,18}$ An analysis by Lin et al ${ }^{10}$ of a MarketScan commercial database consisting of 3,004 patients 
Table 2 Medication adherence

\begin{tabular}{|c|c|c|c|}
\hline Study & Adherence index & Patient subpopulation of interest & AP adherence \\
\hline Haynes et al ${ }^{12}$ & SCAP-HQ ${ }^{\mathrm{a}}$ & Nonremitted vs. remitted cohort & $\begin{array}{l}\text { SCAP-HQ nonadherent: } \\
\text { Baseline: } 1.48 \text { vs. } 1.36 \\
\text { I year: } 1.43 \text { vs. } 1.33 \\
2 \text { years: } 1.39 \text { vs. } 1.30 \\
3 \text { years } 1.3 \text { vs. } 1.30\end{array}$ \\
\hline Joshi et $\mathrm{al}^{16}$ & $\begin{array}{l}\text { MPR } \\
\text { PDC }\end{array}$ & $\begin{array}{l}\text { Incident schizoaffective disorder vs. } \\
\text { prevalent schizoaffective disorder }\end{array}$ & $\begin{array}{l}\text { MPR } \geq 80 \%: 44.9 \% \text { vs. } 58.7 \%(p<0.001) \\
\text { PDC } \geq 80 \%: 33.6 \% \text { vs. } 48.5 \%(p<0.001)\end{array}$ \\
\hline Kim et al ${ }^{17}$ & MMAS $^{b}$ & With (vs. without) copayment burden & $\begin{array}{l}\text { Adherence (MMAS }<2): 58.4 \% \text { vs. } 68.7 \%(p=0.049) \\
\text { Complete adherence (MMAS =0): } 28.5 \% \text { vs. } 46.7 \% \\
(p=0.001)^{c}\end{array}$ \\
\hline Lang et $\mathrm{al}^{7}$ & $\begin{array}{l}\text { MPR } \\
\text { Maximum continuous } \\
\text { gap in treatment }\end{array}$ & $\mathrm{N} / \mathrm{A}$ & $\begin{array}{l}\text { Percentage with MPR < } 80 \%: 44.6 \% \\
\text { Maximum continuous gap in treatment (days): } 38.8\end{array}$ \\
\hline Offord et $\mathrm{al}^{2}$ & MPR & $\begin{array}{l}\text { Early nonadherent (vs. early adherent) } \\
\text { cohort }\end{array}$ & MPR: 0.22 vs. $0.73(p<0.0001)$ \\
\hline Offord et al ${ }^{18}$ & MPR & LAI (vs. oral AP) users & MPR: 0.67 vs. $0.56(p<0.001)$ \\
\hline Pyenson et al $^{19}$ & Compliance rate $^{d}$ & No subpopulation of interest & Average compliance rate: $61.0 \%$ \\
\hline \multicolumn{4}{|c|}{ 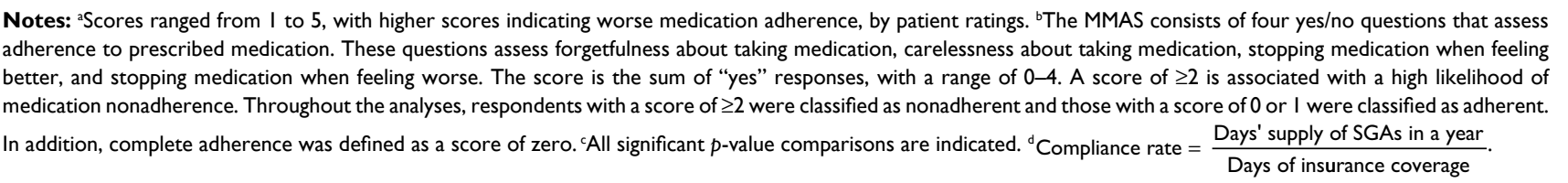 } \\
\hline
\end{tabular}

Abbreviations: AP, antipsychotic; LAI, long-acting injectable AP; MMAS, Morisky Medication Adherence Scale; MPR, medication possession ratio; PDC, proportion of days covered; SCAP-HQ, Schizophrenia Care and Assessment Program Health Questionnaire; N/A, not applicable; SGA, second-generation AP.

with schizophrenia who initiated LAIs $(n=394)$ or oral APs ( $n=2,610)$ from 2005 to 2010 showed that adherence was significantly higher during the post-index period on LAIs compared to either the pre-LAI baseline or oral APs.

These data were supported by Peng et al's study of 147 patients with schizophrenia who initiated LAIs and had records in the Thomson Medstat MarketScan Commercial Claims and Encounters Database from January 1, 2004, to March 31, 2008. Mean MPR increased from 0.368 within 6 months before initiating LAIs to 0.600 within 6 months afterward $(p<0.001){ }^{24}$

\section{Clinical burden of polypharmacy}

One study report was appropriate for, and reviewed in, this section. ${ }^{20}$

Patients with schizophrenia who received prescriptions for $\geq 1$ AP, especially younger individuals around the time of the incident schizophrenia event, experienced significantly reduced adherence to these regimens compared to those receiving prescriptions for monotherapy. ${ }^{20}$ In a study of 4,156 patients included in the HealthCore Integrated Research Environment (HIRE) database from January 1, 2007, to April 30, 2010, 968 (23.3\%) patients received polypharmacy (vs. monotherapy) and had significantly reduced adherence to these regimens, especially younger individuals. ${ }^{20}$

\section{Key findings on HE burden}

\section{HE burden of nonremission}

One study report was appropriate for, and reviewed in, this section. $^{12}$

Studying 2,327 adults with schizophrenia in the prospective US-SCAP trial, Haynes et $\mathrm{al}^{12}$ found that health care costs were significantly higher in nonremitted (vs. remitted) patients across 3 years.

\section{HE burden of nonadherence and effects of LAI regimens}

Nine reports of six studies provided data on medication nonadherence $\mathrm{e}^{2,7,10,12,15-19}$ (three reports involved the same study population $\left.{ }^{2,10,18}\right)$. A claims database study of patients in the Truven MarketScan ${ }^{\circledR}$ Commercial Claims and Encounters database who initiated oral APs from January 1, 2006, to September 30, 2009, revealed significant increases in numbers of all-cause and schizophrenia-specific hospitalizations, as well as mean LOS values associated with each type of admission, among patients who were early nonadherers compared to early adherers (within 90 days of the index schizophrenia event; Table 3). ${ }^{2}$

Another Truven MarketScan analysis, of 394 patients who initiated LAIs from January 1, 2005, to September 30,2010 , reported significant reductions in all-cause 
Table 3 Health resource utilization (HRU) and costs for privately insured US patients with schizophrenia: comparisons across all studies

\begin{tabular}{|c|c|c|c|c|c|c|}
\hline \multirow[t]{2}{*}{ Study } & \multirow[t]{2}{*}{ Data source } & \multirow[t]{2}{*}{ Time frame } & \multirow{2}{*}{$\begin{array}{l}\text { Patient } \\
\text { subpopulation } \\
\text { of interest } \\
\end{array}$} & \multicolumn{3}{|c|}{ All-cause HRU and costs } \\
\hline & & & & Hospitalization & ED visit & Costs \\
\hline $\begin{array}{l}\text { Cloutier } \\
\text { et al" }\end{array}$ & $\begin{array}{l}\text { Truven } \\
\text { MarketScan } \\
\text { Commercial } \\
\text { Claims Database }\end{array}$ & 2013 & $\begin{array}{l}\text { Patients with } \\
\text { schizophrenia }\end{array}$ & $\mathrm{N} / \mathrm{A}$ & $\mathrm{N} / \mathrm{A}$ & $\begin{array}{l}\text { Per-capita costs: } \\
\text { Medication }=\$ 3,500 \\
\text { Outpatient }=\$ 2,468 \\
\text { Inpatient }=\$ 5,160 \\
\text { ED }=\$ 87 \mid \\
\text { Other medical }=\$ 28 \mathrm{I} \\
\text { Total }=\$ 12,46 \mathrm{I}^{\mathrm{a}}\end{array}$ \\
\hline Fitch et $\mathrm{a}^{26}$ & $\begin{array}{l}\text { Truven } \\
\text { MarketScan } \\
\text { Commercial } \\
\text { Claims } \\
\text { Database }\end{array}$ & $2007-2011$ & $\begin{array}{l}\text { Patients with (vs. } \\
\text { without) SCZ }\end{array}$ & $\begin{array}{l}\text { Annual inpatient } \\
\text { admissions per } 1,000 \\
\text { patients: } 636 \text { vs. } 48\end{array}$ & $\begin{array}{l}\text { Annual ED } \\
\text { visits per } 1,000 \\
\text { patients: } 2,270 \\
\text { vs. } 158\end{array}$ & $\begin{array}{l}\text { Mean cost PPPM: } \\
\text { Inpatient cost: } \$ 762 \text { vs. } \$ 97 \\
\text { Outpatient cost: } \$ 592 \text { vs. } \$ 239 \\
\text { Prescription drug cost: } \$ 452 \\
\text { vs. } \$ 83\end{array}$ \\
\hline $\begin{array}{l}\text { Offord } \\
\text { et al }{ }^{18}\end{array}$ & $\begin{array}{l}\text { Truven } \\
\text { MarketScan } \\
\text { Commercial } \\
\text { Claims } \\
\text { Database }\end{array}$ & $\begin{array}{l}\text { January } \\
\text { I, 2005- } \\
\text { September } \\
30,2010\end{array}$ & LAl vs. oral AP & $\begin{array}{l}\text { Mean difference } \\
\text { in the number of } \\
\text { hospitalizations: }-0.90 \\
\pm 1.77 \text { vs. } 0.02 \pm 1.49 \\
\text { Mean difference in } \\
\text { the total LOS (days): } \\
-10.3 \pm 23.2 \text { vs. } 0.7 \pm \\
16.7 \text { days }\end{array}$ & N/A & N/A \\
\hline \multicolumn{7}{|c|}{ Early nonadherent vs. early adherent } \\
\hline $\begin{array}{l}\text { Offord } \\
\text { et } \mathrm{al}^{2}\end{array}$ & $\begin{array}{l}\text { Truven } \\
\text { MarketScan } \\
\text { Commercial } \\
\text { Claims } \\
\text { Database }\end{array}$ & $\begin{array}{l}\text { January I, } \\
2006 \text { to } \\
\text { September } \\
30,2009\end{array}$ & $\begin{array}{l}\text { Early } \\
\text { nonadherent (vs. } \\
\text { early adherent) } \\
\text { to oral APs }\end{array}$ & $\begin{array}{l}\text { Number of } \\
\text { hospitalizations, mean } \\
\pm \text { SD: } 0.57 \pm 1.08 \text { vs. } \\
0.38 \pm 0.90 \\
\text { Total LOS (days in } \\
\text { hospital), mean } \pm \\
\text { SD: } 5.0 \pm 13.6 \text { vs. } 3.0 \\
\pm 8.6\end{array}$ & $\mathrm{~N} / \mathrm{A}$ & $\begin{array}{l}\text { All-cause hospitalization cost: } \\
\$ 5,850 \text { vs. } \$ 4,21 \text { I }(p=0.024) \\
\text { SCZ-related hospitalization cost: } \\
\$ 2,952 \text { vs. } \$ 1,969(p=0.0465) \\
\text { Total annual per-capita cost: } \\
\$ 5,358 \text { vs. } \$ 6,660(p=0.02 I) \\
\text { Total annual pharmacy per- } \\
\text { capita cost: } \$ 1,549 \text { vs. } \$ 3,684 \\
(p<0.000 \text { I) }\end{array}$ \\
\hline $\begin{array}{l}\text { Nicholl } \\
\text { et a }\left.\right|^{14}\end{array}$ & $\begin{array}{l}\text { PharMetrics } \\
\text { Integrated } \\
\text { Database }\end{array}$ & 1998-2007 & $\begin{array}{l}\text { Recently } \\
\text { diagnosed } \\
\text { patients vs. } \\
\text { chronic patients }\end{array}$ & $\begin{array}{l}\% \text { hospitalized: } 22.3 \% \\
\text { vs. I2.4\% ( } p<0.000 I) \\
\text { Mean number of days } \\
\text { in hospital: } 5.1 \text { vs. } 3.0 \\
(p=0.0065)\end{array}$ & $\begin{array}{l}\text { \% of patients: } \\
24.6 \% \text { vs. } 17.5 \% \\
(p<0.0001) \\
\text { Mean number } \\
\text { of admissions: } \\
0.48 \text { vs. } 0.36 \\
(p=0.0019)\end{array}$ & $\begin{array}{l}\text { Total mean annual per-capita } \\
\text { health care cost: } \$ 20,654 \text { vs. } \\
\$ 15,489(p<0.0001)\end{array}$ \\
\hline Peng et $\mathrm{a}^{24}$ & $\begin{array}{l}\text { Thomson } \\
\text { Medstat } \\
\text { MarketScan } \\
\text { Commercial } \\
\text { Claims and } \\
\text { Encounters } \\
\text { databases }\end{array}$ & $\begin{array}{l}\text { January I, } \\
\text { 2004-March } \\
31,2008\end{array}$ & $\begin{array}{l}\text { 6-month pre- vs. } \\
\text { 6-month post- } \\
\text { depot initiation }\end{array}$ & $\begin{array}{l}\text { Proportion } \\
\text { hospitalized for any } \\
\text { reason: } 53.7 \% \text { vs. } \\
29.9 \% \\
\text { Days hospitalized for } \\
\text { any reason, mean: } 8.0 \\
\text { vs. } 5.3\end{array}$ & N/A & $\begin{array}{l}\text { Total per-capita health care } \\
\text { costs: } \$ 7,884 \text { after LAI vs. } \\
\$ 1 \text { I, I I I before LAI } \\
(p<0.05) \\
\text { Psychiatric hospitalization costs: } \\
\$ 2,538 \text { after LAI vs. } \$ 5,384 \\
\text { before LAI }(p<0.05)\end{array}$ \\
\hline $\begin{array}{l}\text { Wilson } \\
\text { et } a^{2 !}\end{array}$ & $\begin{array}{l}\text { Claims database } \\
\text { analysis of a } \\
\text { private insurer }\end{array}$ & $\begin{array}{l}\text { June } 2001- \\
\text { May } 2004\end{array}$ & $\begin{array}{l}\text { Newly diagnosed } \\
\text { patients vs. } \\
\text { previously } \\
\text { diagnosed } \\
\text { patients }\end{array}$ & $N / A$ & $N / A$ & $\begin{array}{l}\text { Total: } \$ 15,282 \text { vs. } \$ 12,029 \\
(p=0.09) \\
\text { Total inpatient services: } \$ 7,745 \\
\text { vs. } \$ 4,440(p=0.03) \\
\text { Total prescriptions: } \$ 3,165 \text { vs. } \\
\$ 4,548(p=0.002)\end{array}$ \\
\hline
\end{tabular}

Note: aAll costs not included in total.

Abbreviations: AP, antipsychotic; ED, emergency department; LAI, long-acting injectable AP; LOS, length of stay; N/A, not available or not applicable; PPPM, per patient per month; SCZ, schizophrenia.

and schizophrenia-related hospitalization costs and total annual per-capita costs after (vs. before) initiating LAIs (Table 3). ${ }^{18}$
In two different studies of the same population of privately insured patients with schizophrenia, mean all-cause and schizophrenia-related hospitalization costs significantly 
decreased after (vs. before) initiating LAIs (Table 3). ${ }^{10,18}$ Mean all-cause hospitalizations after initiating LAIs decreased from 1.60 days to 0.7 day $(p<0.001) .{ }^{10}$ The corresponding decrease in LOS after initiating LAIs was 10.3 days for all-cause hospitalizations $(p<0.001$; Table $3) .{ }^{10}$ Increased adherence and prescription drug costs were offset by annual reductions in costs for both all-cause and schizophrenia-related hospitalizations. Conversely, patients who initiated oral APs experienced significant increases in these costs (Table 3 ). ${ }^{10}$

In the study by Peng et $\mathrm{al}^{24}$ of 147 patients with schizophrenia, health resource utilization (HRU) and costs declined significantly at 6 months after (vs. 6 months before) initiating LAIs. Proportions of patients with psychiatric hospitalizations decreased from $49.7 \%$ to $22.4 \%(p<0.001)$, and the mean LOS of psychiatric hospitalizations decreased from 7.3 to 4.7 days $(p=0.054)$. Introduction of LAIs was also associated with significant decreases in all-cause health care costs, which were largely due to a significant decrease in psychiatric hospitalization cost (Table 3).

A hospital claims database analysis from 2006 to 2010 by Lafeuille et $\mathrm{al}^{27}$ examined HRU in relapsed patients with schizophrenia using oral APs who either remained on these medications or switched to LAIs. During 30 months of follow-up, patients using LAIs (vs. oral APs) had significantly fewer emergency department (ED) visits and rehospitalizations, with significantly $(12 \%-19 \%)$ reduced likelihoods of each (hazard ratio [HR] $0.88,95 \% \mathrm{CI}=0.87-0.93[p<$ $0.0001]$ for $\mathrm{ED}$ visits and $\mathrm{HR}=0.81 ; 95 \% \mathrm{CI}=0.76-0.87$ $[p<0.0001]$ for rehospitalizations).

\section{HE burden of polypharmacy}

One study report was appropriate for, and reviewed in, this section. $^{23}$

A claims database analysis by $\mathrm{McCombs}$ et $\mathrm{al}^{23}$ found that patients with schizophrenia who initiated treatment with $\geq 2$ medications were more likely to be hospitalized during the first year (42.2\% vs. 34.0\%) and incur greater associated per-capita costs $(\$ 12,806$ vs. $\$ 9,413)$ compared to those receiving monotherapy.

\section{HE burden of incident (vs. prevalent) disease}

Two study reports were appropriate for, and reviewed in, this section. ${ }^{14,21}$

One study that examined a privately insured patient population with schizophrenia in California $(\mathrm{N}=414)$ from June 2001 to May 2004 found that, during a 12-month treatment period, newly diagnosed patients had significantly lower costs for all-cause $(p=0.0002)$ and schizophrenia-specific ( $p=0.02$ ) medication prescriptions compared to previously diagnosed individuals (Table 3). However, the newly (vs. previously) diagnosed patients also incurred significantly greater expenses for inpatient services (total $p=0.03$; schizophrenia-specific $p=0.04$ ) and all-cause outpatient medical care $(p=0.01){ }^{21}$

Another study, conducted by Nicholl et al, ${ }^{14}$ similarly assessed medical and pharmaceutical claims data for patients recently diagnosed with schizophrenia, approximately $80 \%$ of whom were covered by private insurance plans. These researchers demonstrated that patients with recently diagnosed (vs. chronic) schizophrenia had a higher rate of psychiatric hospitalization ( $22.3 \%$ vs. $12.4 \% ; p<0.0001)$. Resource allocation was also higher in patients with recently diagnosed illness, who had a longer average LOS in hospital (5.1 vs. 3.0 days; $p=$ 0.0065 ) and made more frequent use of ED resources (Table $3)$. There was also a nearly twofold increase in mean annual per-capita health care costs in the year after (vs. before) schizophrenia was diagnosed (\$20,654 vs. $\$ 10,177 ; p<0.0001)$. Finally, difficulties in coping within the first year after incident schizophrenia may be reflected by a two- to fivefold increase in frequencies of alcohol or drug dependence (or substance abuse) and suicidal behaviors in recently diagnosed patients with schizophrenia who were enrolled in the PharMetrics Integrated Database from 1998 to 2007.

\section{Discussion}

This systematic literature review synthesized RWE for patients with schizophrenia over the past decade from the US private insurance payer perspective and highlighted the fact that privately insured patients with schizophrenia experienced a substantial clinical and economic burden, including suboptimal health outcomes. The outcomes examined in the current review ranged widely and included comorbidity, polypharmacy, nonremission or relapse, and treatment adherence.

Research on privately insured patients with schizophrenia has been minimal, with only 25 peer-reviewed journal articles identified in the current systematic literature review. On the other hand, the evidence presented in this study resembles findings reported for publicly insured populations (i.e., Medicaid, Medicare, and Veterans Affairs). ${ }^{7,10,18,30,32}$

Published literature on Medicaid recipients and other publicly insured patients suggests that these individuals with schizophrenia may have more adverse clinical and economic outcomes, which can be attributed primarily to comorbidities, polypharmacy, less continuity of care, relapse, and poor 
medication adherence. For example, Williams et $\mathrm{al}^{32}$ found that Medicaid payment status was significantly correlated with an approximately threefold elevation in the risk of AP polypharmacy $(\mathrm{OR}=2.73 ; 95 \% \mathrm{CI}=1.11-6.68 ; p=0.03)$ compared to other forms of insurance or no insurance.

Further, in Citrome et al's study ${ }^{33}$ of Truven Health Analytics MarketScan ${ }^{\circledR}$ Multi-State Medicaid and Commercial insurance claim databases, prevalences of certain potentially treatment-limiting adverse risk factors (i.e., extrapyramidal symptoms, diabetes, obesity, QT interval prolongation, and hyperprolactinemia) were higher in Medicaid (vs. privately insured) patients with schizophrenia. In an analysis of the Truven Multi-State Medicaid and IMS LifeLink Health Plan claims data from 2008 to 2009 , Lang et $\mathrm{al}^{7}$ also reported that the mean (SD) cost per all-cause hospitalization in patients with schizophrenia was $\$ 14,528(\$ 21,113)$ in Medicaid patients compared to $\$ 9,796(\$ 11,462)$ in privately insured individuals.

Long-acting medication regimens for schizophrenia have been found to be effective in improving treatment adherence and reducing risks of relapse and hospitalization in both privately and publicly insured populations. For example, the analyses of the Truven MarketScan database by Offord et al $^{18}$ identified statistically significant improvements in AP adherence and reductions in hospitalizations, LOS, and mean costs, after (vs. before) initiating LAIs in 665 Medicare (as well as in 3,004 privately insured) patients with schizophrenia. ${ }^{10}$ Similarly, Lafeuille et $\mathrm{al}^{27}$ found that there was a $36 \%$ relative risk reduction in rehospitalization with LAIs compared to oral APs, in an analysis of electronic medical record data from the Premier Perspective Comparative Hospital Database (Premier).

Long-acting injectable therapies are generally available via hospital formularies and have also shown potential to alleviate clinical and economic burden associated with schizophrenia, but the overall use of these agents remains relatively low in both publicly and privately insured populations. In this review, only $0.25 \%-13.1 \%$ of privately insured patients were treated with LAIs across all studies. ${ }^{10,16,18}$ A broad literature review on AP adherence concluded that "LAIs represent a valuable option for treating schizophrenia given the known improvement in adherence, and yet these formulations are largely underutilized."4

Although LAI therapies were found to have favorable effects in limiting the economic burden of schizophrenia management, these observations were made in only three studies. ${ }^{7,10,18}$ Our findings should be corroborated in larger and more heterogeneous patient populations assessed in pragmatic, longitudinal studies. Ongoing issues related to LAI use include the settings in which to initiate treatment, such as first-episode psychosis and acute exacerbations of schizophrenia in a setting of prior nonadherence. ${ }^{34}$

The focused scope of our systematic literature review may have precluded consideration of potential barriers to LAI use, including prior authorization requirements. ${ }^{35,36}$ The clinical and economic benefits in patients treated with LAIs across multiple observational studies in the present review suggest that access to LAIs within private health plans should be further assessed.

Our review also found that little information is available on young adult, privately insured patients with schizophrenia, despite the health care expansion mandate that young patients (aged $\leq 26$ years) be eligible for coverage under their parents' health insurance plans. Notably, although the onset of schizophrenia usually occurs in an individual's early 20 s, an accurate schizophrenia diagnosis may not be made until several years after incident psychosis.

Future research is needed to better understand the humanistic, clinical, and economic burden of schizophrenia. Such work might include meta-analyses if data are sufficiently homogeneous to be pooled. The field might be advanced by conducting a similar systematic literature review to the current study, or a meta-analysis, that also encompasses larger numbers of studies of more diverse patient populations with both employer-based and public health insurance. Other potential future lines of inquiry might involve assessments of: 1) patients with either public or commercial health insurance; 2) ex-US societies, including those with different prevailing forms of coverage (e.g., universal health care); 3 ) indirect and direct health care costs; 4) different patient profiles (including different age strata and "patient journeys"); and 5) distinct perspectives aside from that of the payer taken in our review (e.g., patient's or caregiver's perspective).

\section{Limitations}

Despite the rigorous methodology employed in this review, it is not without limitations. For example, 24 of the 25 peerreviewed articles included in this review were retrospective, observational cohort studies of administrative claims databases. The observational nature of the studies analyzed does not enable us to conclusively rule out biases and exclude confounding on unmeasured variables, especially given that certain databases (e.g., MarketScan) analyzed in the base studies were derived from large, nonrandom (convenience) samples.

International Classification of Diseases codes used to identify patients in these studies were developed for reimbursement, not case ascertainment, purposes, opening the 
possibility of coding errors. Reported costs were as identified in each study and not corrected to any single inflationadjusted annual currency values or 2016-2017 dollars. Because our study was specifically designed to evaluate US residents, its findings cannot necessarily be extrapolated to other (ex-US) populations with potentially divergent health delivery systems and practices. ${ }^{37}$

Although the EMBASE/MEDLINE searches were exhaustive, given the prespecified eligibility criteria, the amount of information was still confined to only 25 peerreviewed studies, of which fewer than half(10) included only privately insured patients: $45.5 \%$ of the total study sample population in all studies that were included. The 81,327 privately insured patients reported in the "Results" section may overestimate the actual number of patients studied, because this number did not necessarily include unique patients; certain studies (including those by Offord et al, ${ }^{2}$ Lin et al, ${ }^{10}$ and Offord et $\mathrm{al}^{18}$ ) evaluated the same population.

Variables analyzed in the 25 studies were too divergent to enable meaningful pooling of the data or conducting more rigorous statistical tests of publication bias (e.g., by funnel plots) and heterogeneity (e.g., by the $I^{2}$ test). In addition to a large plurality of variables contributing to the cost of burden of schizophrenia in employer-based health systems, there were relatively few studies available for each, prespecified cost component of interest. Overall, these factors precluded pooling of the data and conducting a meta-analysis, which might have otherwise strengthened our study findings.

\section{Conclusion}

Privately insured patients with schizophrenia are confronted with a substantial clinical and economic burden related to comorbidities, acute care needs, treatment nonadherence, and polypharmacy. Although not prevalent, treatment with LAIs has been shown to significantly promote adherence and reduce both overall HRU and direct health care costs, such as all-cause and schizophrenia-related hospitalization. On the basis of this systematic literature review, further research is warranted to better understand prescribing patterns and clinical policies related to managing schizophrenia and optimal ways to enhance patient outcomes.

\section{Acknowledgment}

This study and its report were supported by Janssen Scientific Affairs, LLC (Titusville, NJ, USA), which had a role in the design of the study, drafting of the manuscript, and the decision to report the findings.

\section{Author contributions}

All authors were involved in study design. WZ and SWG were involved in data acquisition. All authors were involved in data interpretation. SWG and WZ were involved in drafting the manuscript, and all other authors provided substantive intellectual contributions to the text and graphics. All authors reviewed and approved the final draft and take full responsibility for the study, its findings, and this report.

\section{Disclosure}

WZ, SWG, and NL are employed by WG AHA, which consults with Janssen Scientific Affairs, LLC, and other life science companies. They have no other financial interests to disclose. KJ \& TBA are employees of Janssen Scientific Affairs, LLC and shareholders of Johnson \& Johnson. When the study was conducted and the manuscript drafted, EG was an employee of WG AHA. The authors report no other conflicts of interest in this work.

\section{References}

1. Schizophrenia and Related Disorders Alliance of America [homepage on the Internet]. Schizophrenia and Related Disorders Alliance of America: About Schizophrenia. Available from: http://www.sardaa.org/. Accessed March 29, 2018.

2. Offord S, Lin J, Mirski D, Wong B. Impact of early nonadherence to oral antipsychotics on clinical and economic outcomes among patients with schizophrenia. Adv Ther. 2013;30(3):286-289.

3. Kennedy JL, Altar CA, Taylor DL, Degtiar I, Hornberger JC. The social and economic burden of treatment-resistant schizophrenia. Int Clin Psychopharmacol. 2014;29(2):63-76.

4. Kaplan G, Casoy J, Zummo J. Impact of long-acting injectable antipsychotics on medication adherence and clinical, functional, and economic outcomes of schizophrenia. Patient Prefer Adherence. 2013;7:1171-1180.

5. Fuller-Thomson E, Hollister B. Schizophrenia and suicide attempts: findings from a representative community-based Canadian sample. Schiz Res Treat. 2016;3165243:1-11.

6. Khaykin E, Eaton W, Ford D, Anthony C, Daumit G. Health insurance coverage among persons with schizophrenia in the United States. Psychiatr Serv. 2010;61(8):830-834.

7. Lang K, Federico V, Muser E, Menzin J, Menzin J. Rates and predictors of antipsychotic non-adherence and hospitalization in Medicaid and commercially-insured patients with schizophrenia. J Med Econ. 2013;16(8):997-1006.

8. Centers for Medicare \& Medicaid Services [webpage on the Internet]. Young Adults and the Affordable Care Act: Protecting Young Adults and Eliminating Burdens on Families and Businesses; 2010. Available from: https://www.cms.gov/CCIIO/Resources/Files/adult_child_fact_sheet. html. Accessed May 19, 2017.

9. Wu EQ, Birnbaum HG, Shi L, et al. The economic burden of schizophrenia in the United States in 2002. J Clin Psych. 2005;66: $1122-1129$.

10. Lin J, Wong B, Offord S, Mirski D. Healthcare cost reductions associated with the use of LAI formulations of antipsychotic medications versus oral among patients with schizophrenia. J Behav Health Serv Res. 2013;40(3):355-366.

11. Cloutier M, Sanon Aigbogun M, Guerin A, et al. The economic burden of schizophrenia in the United States in 2013. J Clin Psychiatry. 2016;77(6):764-771. 
12. Haynes VS, Zhu B, Stauffer VL, et al. Long-term healthcare costs and functional outcomes associated with lack of remission in schizophrenia: a post-hoc analysis of a prospective observational study. BMC Psychiatry. 2012;12(1):222.

13. Carney CP, Jones L, Woolson RF. Medical comorbidity in women and men with schizophrenia: A population-based controlled study. J Gen Intern Med. 2006;21(11):1133-1137.

14. Nicholl D, Akhras KS, Diels J, Schadrack J. Burden of schizophrenia in recently diagnosed patients: healthcare utilisation and cost perspective. Curr Med Res Opin. 2010;26(4):943-955.

15. Gibson TB, Jing Y, Kim E, et al. Cost-sharing effects on adherence and persistence for second-generation antipsychotics in commercially insured patients. Manag Care. 2010;19(8):40-47.

16. Joshi K, Lin J, Lingohr-Smith M, Fu D-J, Muser E. Treatment patterns and antipsychotic medication adherence among commercially insured patients with schizoaffective disorder in the United States. J Clin Psychopharmacol. 2016;36(5):429-435.

17. Kim E, Gupta S, Bolge S, Chen C-C, Whitehead R, Bates JA. Adherence and outcomes associated with copayment burden in schizophrenia: a cross-sectional survey. J Med Econ. 2010;13(2):185-192.

18. Offord S, Wong B, Mirski D, Baker RA, Lin J. Healthcare resource usage of schizophrenia patients initiating long-acting injectable antipsychotics vs oral. J Med Econ. 2013;16(2):231-239.

19. Pyenson B, Goldberg S, Iwasaki K, Boyarsky V, Dirani R. A Medicaid and commercial insured claims-based study to estimate improved antipsychotic medication adherence among patients with schizophrenia. J Behav Health Serv Res. 2013;40(2):222-233.

20. Fisher MD, Reilly K, Isenberg K, Villa KF. Antipsychotic patterns of use in patients with schizophrenia: polypharmacy versus monotherapy. BMC Psychiatry. 2014;14:341.

21. Wilson LS, Gitlin M, Lightwood J. Schizophrenia costs for newly diagnosed versus previously diagnosed patients. Am J Pharm Benefits. 2011;3(2):107-115.

22. Rost K, Hsieh YP, Xu S, Menachemi N, Young AS. Potential disparities in the management of schizophrenia in the United States. Psychiatr Serv. 2011;62(6):613.

23. McCombs J, Zolfaghari S, Ganapathy V. Impact of drug treatment history on comparative effectiveness research in schizophrenia. Value Health. 2011;14(5):679-686.

24. Peng X, Ascher-Svanum H, Faries D, Conley RR, Schuh KJ. Decline in hospitalization risk and health care cost after initiation of depot antipsychotics in the treatment of schizophrenia. Clin Outcomes Res. 2011;3(1):9-14.
25. Dodds TJ, Phutane VH, Stevens BJ, Woods SW, Sernyak MJ, Srihari VH. Who is paying the price? Loss of health insurance coverage early in psychosis. Psychiatr Serv. 2011;62(8):878-881.

26. Fitch K, Iwasaki K, Villa KF. Resource utilization and cost in a commercially insured population with schizophrenia. Am Health Drug Benefits. 2014;7(1):18-26.

27. Lafeuille M-H, Laliberté-Auger F, Lefebvre P, Frois C, Fastenau J, Duh MS. Impact of atypical long-acting injectable versus oral antipsychotics on rehospitalization rates and emergency room visits among relapsed schizophrenia patients: a retrospective database analysis. BMC Psychiatry. 2013;13:221.

28. Panish JM, Dirani R, Halpern R, Cao F. Exploratory analysis of psychiatric-related utilization and costs associated with paliperidone ER compared with other oral atypical antipsychotics using pharmacy claims from an administrative database. J Med Econ . 2010;13(4):610-617.

29. Stensland M, Watson PR, Grazier KL. An examination of costs, charges, and payments for inpatient psychiatric treatment in community hospitals. Psychiatr Serv. 2012;63(7):666-671.

30. Wang CC, Farley JF. Patterns and predictors of antipsychotic medication use among the U.S. population: Findings from the Medical Expenditure Panel Survey. Res Social Adm Pharm. 2013;9:263-275.

31. Gianfrancesco F, Rajagopalan K, Wang R. Hospitalization risks in the treatment of schizophrenia. J Clin Psychopharmacol. 2006;26(4):401-404.

32. Williams EO, Stock EM, Zeber JE, et al. Payer types associated with antipsychotic polypharmacy in an ambulatory care setting. $J$ Pharm Health Serv Res. 2012;3(3):149-155.

33. Citrome L, Eramo A, Francois C, et al. Lack of tolerable treatment options for patients with schizophrenia. Neuropsychiatr Dis Treat. 2015;11:3095-3104

34. Sacchetti E, Grunze H, Leucht S, Vita A. Long-acting injection antipsychotic medications in the management of schizophrenia. Evid Based Psychiatric Care. 2015;1:27-36.

35. Seabury SA, Goldman DP, Kalsekar I, Sheehan JJ, Laubmeier K, Lakdawalla DN. Formulary restrictions on atypical antipsychotics: impact on costs for patients with schizophrenia and bipolar disorder in Medicaid. Am J Manag Care. 2014;20(2):e52-e60.

36. Law MR, Ross-Degnan D, Soumerai SB. Effect of prior authorization of second-generation antipsychotic agents on pharmacy utilization and reimbursements. Psychiatric Serv. 2008;59(5):540-546.

37. Mancuso A, Specchia ML, Lovato E, et al. Economic burden of schizophrenia: the European situation. A scientific literature review. Eur $J$ Public Health. 2014;24(suppl_2):351-352. 


\section{Supplementary material}

Table SI Search terms and outcomes

\begin{tabular}{ll}
\hline Index & Description \\
\hline I & Patients \\
& \\
& \\
& $\begin{array}{l}\text { Patients (subgroup: early } \\
\text { diagnosis) } \\
\text { Patients (subgroup: } \\
\text { adolescents and young } \\
\text { adults) } \\
\\
\text { Treatment }\end{array}$ \\
\hline
\end{tabular}

\section{Search terms}

schiz* AND ("insurance" OR "insured" OR "commercially insured" OR "privately insured" OR "employer sponsored insurance" OR "beneficiary" OR "beneficiaries" OR "hmo" OR "PPo" OR "epo" OR "pos" OR "hdhp" OR "truven" OR "claim database" OR "ims" OR "United Health Care" OR "uhc" OR "kaiser*” OR "magellan" OR "blue cross blue shield" OR "WellPoint" OR "wellcare" OR "Aetna" OR "Cigna" OR "Highmark" OR "hcsc")

"early diagnos*” OR "early" OR "newly diagnos*” OR "first episode"

“adolescent* OR “young"

"antipsychotic" OR "antipsychotics" OR “depot" OR "LAl” OR "long-acting” OR "injectable” OR "oral medication"

$3 \quad$ Clinical burden

"relapse" OR "hospitalization" OR "hospital*” OR "admission*” OR "emergency" OR "er" OR

"functioning" OR "cognition" OR "brief psychiatric rating scale” OR "bprs" OR "positive and negative syndrome scale" OR "panss" OR "clinical global impression" OR "cgi” OR "personal and social performance" OR "psp" OR "short form (36) health survey" OR "sf-36" OR "global assessment of functioning (gaf) scale" OR "gaf" OR "quality of life" OR "qol" OR "treatment satisfaction" OR "comorbid" OR "comorbidity" OR "comorbidities" OR "remission" OR "remit" OR "outpatient" OR "inpatient" OR "discontinuation" OR "adherence"

$4 \quad$ Economic burden "relapse" OR "hospitalization" OR "Financial burden" OR "burden" OR "Economic*” OR "cost of illness" $O R$ "cost" $O R$ "finance" $O R$ "financial" $O R$ "resource" $O R$ "utilization" $O R$ "budget" $O R$ "expenditure" OR "expense" OR "money" OR "spending" OR "price" OR "Indirect work loss" OR "absenteeism" OR "Presenteeism" OR "work productivity" OR "work loss" OR "activity impairment"

$5 \quad$ Patient adherence "adherence" OR "nonadherence" OR "non-adherence" OR "adherent" $O R$ "nonadherent" $O R$ "compliance" OR "non-compliance" OR "noncompliance" OR "compliant" OR "non-compliant" $O R$ "concordance" OR "non-concordance" OR "medication concordance" OR "persistence" OR "nonpersistence" OR "nonpersistence" OR "persistent" OR "nonpersistent" OR "Proportion of Days Covered" OR "Continuous Measure of Medication Acquisition" OR "Continuous Multiple Interval Measure of Oversupply" OR "Medication Possession Ratio" OR "Medication Refill Adherence" OR "Continuous Measure of Medication Gaps" OR "Continuous, Single Interval Measure of Medication Acquisition" OR "Proportion of Days Covered" OR "Refill Compliance Rate" OR "Medication Possession Ratio, modified" OR "Dates Between Fills Adherence Rate" OR "Compliance Rate"

6 Publication type

$7 \quad$ Publication time period Combined search strategies

8 Patient + treatment + publication type + year + "Journal Article" OR "Review" 2006-2016

$(1)+(2)+(6)+(7)+$ English only English only

9 Patient + clinical burden +

$(1)+(3)+(5)+(6)+(7)+$ English only publication type + year + English only

10 Patient + economic burden + publication type + year +

$(1)+(4)+(6)+(7)+$ English only English only

ClinicoEconomics and Outcomes Research

\section{Publish your work in this journal}

ClinicoEconomics and Outcomes Research is an international, peerreviewed open-access journal focusing on health technology assessment, pharmacoeconomics and outcomes research in the areas of diagnosis, medical devices, and clinical, surgical and pharmacological intervention. The economic impact of health policy and health systems organization also constitute important areas of coverage. The manuscript management system is completely online and includes a very quick and fair peer-review system, which is all easy to use. Visit http://www.dovepress.com/testimonials.php to read real quotes from published authors. 